\title{
US urges Puerto Rico to start aerial spraying to reduce risk of birth defects
}

\author{
Michael McCarthy
}

Seattle

US officials have urged Puerto Rico's government to start aerial insecticide spraying to control the island's mosquito population, amid concern that thousands of pregnant women in the territory may become infected with the Zika virus, putting their fetuses at risk of severe neurological birth defects.

"We strongly encourage the people of Puerto Rico to consider aerial spraying as this approach is safe for people and a proven way of controlling the spread of mosquitoes that transmit diseases, from Zika to dengue to chikungunya," Gina McCarthy, administrator of the US Environmental Protection Agency, said in a statement.

Although the US government will pay for the cost of spraying, the decision to spray is up to the government of Puerto Rico, which has been debating the issue. The island, which is about the size of Northern Ireland or Cyprus, has a population of just over 3.6 million.

As at 1 July Puerto Rico's Department of Health had received reports of 2387 cases of Zika virus infection, including 339 in pregnant women. The primary vector of the Zika virus, the
Aedes aegypti mosquito, is endemic on the island, and almost all cases have been locally acquired.

McCarthy noted that aerial spraying had been used to control mosquitoes in the continental US for decades. "Our recommendations for mosquito control in Puerto Rico are the same as our recommendations for mosquito control elsewhere in the United States," McCarthy said.

Studies conducted earlier this year found that mosquitoes in Puerto Rico were resistant to all aerial formulations of pyrethroid insecticides, so the federal government is recommending an organophosphate insecticide, called Naled, which has been used on the US mainland for mosquito control after hurricanes and floods.

In an interview with Reuters Tom Frieden, director of the US Centers for Disease Control and Prevention, said that as many as 50 pregnant women a day were becoming infected with Zika virus in Puerto Rico. "If any part of the continental US had the kind of spread of Zika that Puerto Rico has now, they would have sprayed months ago," he said. 